\title{
Neck circumference as screening measure for identifying adolescents with overweight and obesity
}

\author{
Márcia Ferreira Cândido de Souza ${ }^{1}$, Ricardo Queiroz Gurgel ${ }^{2}$, Íkaro Daniel de Carvalho Barreto ${ }^{3}$, \\ Saravanan Shanmugam ${ }^{4}$
}

DOI: http://dx.doi.org/10.7322/jhgd.119302

\begin{abstract}
Objective: To study the neck circumference (NC) cut-off points for identifying excess body weight levels in adolescents from age between 12-17 years.

Methods: Cross-sectional study was conducted using the data from a Brazilian multicentric project called Study of Cardiovascular Risks in Adolescents - ERICA, which included adolescents with age between 12-17 years' residents in two Brazilian cities from the Northeast part of Brazil. Anthropometric measurements and blood pressure data were collected from the adolescent's sample. The mean average in between the adolescents' groups was compared using the Mann-Whitney. The correlation was estimated by Spearman correlation coefficient to evaluate the association between the NC and other anthropometric variables like age, waist circumference (WC), body mass index (BMI) and blood pressure. The ROC curve was used to analyze the predictive validation of NC as well as to determine the cut-off point of overweight and obesity identification among the adolescents.

Results: This study comprised 1474 adolescents with a mean age of $14.59 \pm 1.57$ years, in which $55.3 \%$ were female. It was found a positive correlation between NC and WC; NC and BMI. The cutoff point for overweight according to the NC for male adolescents aged 12 to 14 years was equivalent to $34.1 \mathrm{~cm}$ and for females $32.05 \mathrm{~cm}$. The adolescent male aged 15 to 17 years group the cutoff point was $36.85 \mathrm{~cm}$ and for women $32,95 \mathrm{~cm}$. The cutoffs points for obesity according to the NC for male adolescents aged 12 to 14 years was $34.9 \mathrm{~cm}$ and for females $33.85 \mathrm{~cm}$. In the age group 15-17 years, the cutoff point for obesity for males was $38.4 \mathrm{~cm}$ and for females $35.85 \mathrm{~cm}$.

Conclusions: The neck circumference represented significant correlation among waist circumference and body mass index well stablished indicators of adiposity and can identify adolescents with high body mass index.
\end{abstract}

Key words: obesity, antrophometric, neck, adolescent nutrition.

\section{INTRODUCTION}

The increasing weight in the age group 10-19 years was evidenced in recent decades in countries with different socioeconomic development stages. Regarding obesity numbers among Brazilian male adolescents, the rate has increased from $3.7 \%$ to $21.7 \%$ and among women from $7.6 \%$ to $19.0 \%$ between the years of 1975 to $2009^{1}$

An important strategy to control obesity in Brazil would be to develop a practical method of diagnosis for this disease which is low cost, simple and reliable for the assessment of adolescents, especially in primary care.

There are numerous anthropometric methods used to evaluate overweight and obesity. Some techniques are applicable for primary health care, like weight and height measurement, waist and hip circumference and the calculation in between these measurements; however, there is still controversy about the effectiveness of some methods for measuring overweight/obesity in children and adolescents ${ }^{2}$.

1. Hospital Universitário da Universidade Federal de Sergipe. Aracaju (SE), Brasil.

2. Núcleo de Pós-Graduação em Ciências da Saúde. Universidade Federal de Sergipe. Aracaju (SE), Brasil.

3. Programa de Pós-Graduação em Biometria e Estatística Aplicada - PPGBEA - Universidade Federal Rural de Pernambuco. Pernambuco, Brasil.

4. Departamento de Farmácia. Universidade Federal de Sergipe. Aracaju (SE), Brasil.

Corresponding author: Email: marciacandido@ufs.br

Suggested citation: Souza MFC, Gurgel RQ, Barreto IDC, Saravanan S. Neck circumference as screening measure for identifying adolescents with overweight and obesity. J Hum Growth Dev. 26(2): 260-266. Doi: http://dx.doi.org/10.7322/jhgd.119302.

Manuscript submitted: Feb 2 2016, accepted for publication Feb 292016. 
Body Mass Index is considered to be the main anthropometric measure for evaluating overweight due to its low cost and ease of application ${ }^{3}$, but despite these advantages, several studies have shown numerous points of disagreement about its application to the correct diagnosis of obesity composition ${ }^{4,5}$.

Vague $^{6}$ was the first researcher to realize that different body morphology and body fat distribution type are related to the health risks associated with obesity. He used the neck skin fold in its male differentiation index to assess the fat distribution in the upper body. From Vague study ${ }^{6}$, neck circumference (NC) has been investigated as a screening instrument for overweight individuals because it is easy to measure, low cost; it is not invasive and does not vary throughout the day as it happens with waist circumference ${ }^{6}$. In addition, neck circumference correlates with several studies with other anthropometric measurements related to fat and cardiovascular risk factors. ${ }^{7-9}$

There is a lack of studies that evaluate NC in adolescents. Therefore, considering the ease of obtaining the $\mathrm{NC}$ in epidemiological studies and clinical practice and also the importance of early identification of overweight for prevention of metabolic disorders and diseases in adulthood, the aim of the present study is to measure the $\mathrm{NC}$ cut-off points for identification of overweight levels in adolescents from two cities of Northeast part of Brazil.

\section{METHODS}

\section{Study design}

A cross-sectional study was conducted using data from a national multicenter project named as The Study of Cardiovascular Risks in Adolescents (ERICA) ${ }^{10}$. The main objective of this research was to estimate the prevalence of cardiovascular $r 9$ in isk factors in Brazilian adolescents. In that multicenter study, over 75 thousand students aged between 12 and 17 years were evaluated from 1,248 public and private schools, all distributed in 121 Brazilian municipalities with over 100 thousand inhabitants.

\section{Study sample}

The population from this study corresponds to a subsample from ERICA's project which consists of adolescents aged 12 to 17 years, enrolled in schools from two cities Aracaju and Nossa Senhora do Socorro from the State of Sergipe, Brazilian Northeast. The sample may be considered to have local representativity.

For ERICA's Project sample procedure in Sergipe, twenty nine public and private schools were selected, twenty six located in Aracaju and three in Nossa Senhora do Socorro, the second municipality with over 100,000 inhabitants in Sergipe State. A survey using class year as a proxy of age took place in order to select eligible classes $\left(7^{\text {th }}, 8^{\text {th }}, 9^{\text {th }}\right.$ years of elementary school and $1^{\text {st }}, 2^{\text {nd }}$ and $3^{\text {rd }}$ years of high school) and which allowed three classes to be chosen from each school.

In each selected class, every student evaluated had signed the Informed Consent Form agreeing to participate and be present at the data collecting day.

\section{Groups by age}

The adolescents were divided into two groups with different age levels for evaluation of results determination. Group 1 was composed with individuals aging between 12 to 14 years and the Group 2 aging between 15 to 17 years.

\section{Exclusion Criteria}

The exclusion criteria presented by individuals in this present study were: neck mass presence or neck deformities, goiter, psychomotor retardation, genetic syndromes, liver and kidney disease, metabolic disorders (such as hypothyroidism and hyperthyroidism) and the use of systemic corticosteroid.

\section{Data collection}

All necessary information about this study was collected from schools of the selected municipalities by a previous trained team for the ERICA's project. Anthropometric measurements such as, weight, height, Body Mass Index (BMI) and waist circumference (WC), Blood pressure (BP) data was collected. In addition to the anthropometric data and BP collected by ERICA's team, researchers also measured neck circumference (NC) of the adolescents in the sample. Weight was calculated using an electronic digital scale (Líder®), model P150m, $200 \mathrm{~kg}$ of capacity and $50 \mathrm{~g}$ of precision. For body weight measurement, all adolescents were evaluated without shoes or any extra clothing nor objects in their school uniform pockets. They were positioned in the middle of the scale, both feet together, standing upright, weight evenly on both feet, motionless, arms relaxed alongside, head in anatomical position and back to the display.

Height was determined by a portable and retractable stadiometer (Alturexata ${ }^{\circledR}$ ), with resolution in millimeters and maximum range of 213 centimeters. For height measurement, adolescents removed their shoes and headdresses. They were positioned in the middle of the equipment, standing motionless, erect with arms relaxed alongside and leaning in the stadiometer ruler with the Frankfurt plane parallel to the base.

For body weight and height analyses, Body Mass Index for age (BMI/age) was calculated according to the World Health Organization's (WHO) cutoff points as reference. The cutoff points were: Z-score $<-3$ (malnutrition); Z-score $\geq-3$ and $<-2$ (low weight); Z-score $\geq-2$ and $\leq 1$ (normal weight); Z-score $>1$ (overweight) and $\leq 2$; Z-score $>2$ (obesity).

For waist circumference (WC) it was used an inelastic fiber glass anthropometric tape (Sanny®) with resolution in millimeters and length of 1.5 meters. WC was measured with the adolescent in the standing- upright position, with abdomen relaxed and arms crossed over the chest. The measurement was done at the midpoint between the lower costal border, from the last rib and the iliac crest, in the axillary midline.

Blood pressure was measured using a digital device Omron ${ }^{\circledR}, 705-I T$, validated for use in adolescents. For this measurement, the adolescent remained sitting with their feet on the floor and the pressure was only measured after 5 minutes of rest. The measurement was taken with the extended right arm resting on the table at heart level. Three 
consecutive measures for each individual were taken between each, with three minutes intervals. The first reading was discarded and used the average of the last two.

Neck circumference (NC) was measured by the team of researchers comprised dietitians and nutrition graduate students, properly trained for technical standardization, using an inelastic fiberglass tape (Sanny $\left.{ }^{\circledR}\right)$, with resolution in millimeters and extension 1.5 meters. The NC measurement was carried out with the child standing and head positioned in the Frankfurt horizontal plane. The researcher made the teenager's neck palpation to locate the cricoid cartilage, which positioned the tape exerting minimum pressure at the time of taking the measure for better contact of the tape with the skin.

\section{Ethical issues}

The ERICA project was approved by the Research Ethics Committees (REC) of the Institute of Collective Health Studies of the Universidade Federal do Rio de Janeiro, under No. 0027.0.239.000-08 and locally by the Research Ethics Committee of the Universidade Federal de Sergipe under the register number CAAE 05185212.2.2033.5546.

\section{Statistical analyses}

Data were analyzed using the R program. For descriptive analysis, mean and standard deviations were calculated relating to age, anthropometric variables and blood pressure. Mann-Whitney test was used to compare the averages between groups of adolescents by gender and age.

The Spearman correlation coefficient was used to assess the association between $\mathrm{NC}$ and other continuous variables such as age, $\mathrm{WC}, \mathrm{BMI}$ and blood pressure.

$\mathrm{NC}$ predictive validity was analyzed by ROC curves (Receiver Operating Characteristic) as well as the determination of cutoff points for identifying overweight and obesity in adolescents in the sample.

For each cutoff point, sensitivity (SE) and specificity (SP) values were calculated and placed in the ROC curve graph which shows on the ordinate axis the sensitivity and the abscissas complement of specificity. The area under curve (AUC) describes the probability of correctly identified individuals that are true positives and those that are not. The higher "cutoff point" greater specificity of the test and the lower the sensitivity. The smaller the "cutoff point" greater sensitivity and is lower specificity. A good score will have an AUC value of 1 . Therefore, the closer to 1.0 the higher sensitivity and specificity will be ${ }^{11}$.

For this study, patients were considered as truepositive results those with high $\mathrm{BMI}$ and $\mathrm{NC}$ values; truenegative those with low BMI and $\mathrm{NC}$ values; false positives those individuals with high $\mathrm{NC}$ values and low $\mathrm{BMI}$ and false-negative those with low $\mathrm{NC}$ values and high BMI. Sensitivity was calculated as true positives (true positives + false negatives) and specificity as true negatives (true negatives + false positives).

The positive predictive value (PPV) was defined as the percentage of subjects with high BMI and NC. Negative predictive value (NPV) was defined as the percentage of subjects with low BMI and NC. The higher the incidence of patients with a high BMI and NC values, higher is the PPV and lower is the NPV and vice versa.

The tests used to calculate the optimal cutoff points were: Maximum Efficiency (maximizes the true positives and true negatives), Youden (maximizes efficiency and sensitivity simultaneously) and Maximizing Cohen's kappa (maximizing the correlation between the predicted value and the expected value). Normality was verified using the Kolmogorov-Smirnov test and significance level of $5 \%(\mathrm{p}<0.05)$.

\section{RESULTS}

A total of 1474 adolescents met the inclusion criteria for this study with mean age $14.59 \pm 1.57$ years, in which $55.3 \%$ were female. Regarding the education level, $51.8 \%$ of adolescents were attending high school and $50.3 \%$ went to public schools. The classification of nutritional status according to BMI showed that $3.8 \%$ of adolescents were underweight and $10.4 \%$ were obese. The general characterization of adolescents of the sample is described in Table 1.

Table 1: Characterization by age group of the adolescent sample enrolled in public and private schools in Sergipe, Brazil.

\begin{tabular}{|c|c|c|c|}
\hline \multirow[t]{2}{*}{ VARIABLES } & \multicolumn{3}{|c|}{ AGE GROUP } \\
\hline & $\begin{array}{l}12-14 \text { years } \\
(M+S D) a\end{array}$ & $\begin{array}{c}\text { 15-17 years } \\
(\mathbf{M}+\mathrm{SD}) \mathbf{a}\end{array}$ & $\begin{array}{c}\text { Total } \\
(\mathbf{M}+\mathbf{S D}) \mathbf{a}\end{array}$ \\
\hline Age (years) & $13.17+0.78$ & $15.9+0.77$ & $14.59+1.57$ \\
\hline $\begin{array}{l}\text { School Level } \\
\left.\text { Primary school ( } 5^{\text {th }} \text { to } 9^{\text {th }} \text { grade }\right) \\
\text { High school }\left(1^{\text {st }} \text { to } 3^{\text {rd }} \text { grade }\right)\end{array}$ & $\begin{array}{c}n(\%) \\
334(47.1) \\
375(52.9)\end{array}$ & $\begin{array}{c}n(\%) \\
376(49.2) \\
389(50.8)\end{array}$ & $\begin{array}{c}\mathrm{n}(\%) \\
710(48.1) \\
764(51.8)\end{array}$ \\
\hline $\begin{array}{l}\text { School type } \\
\text { Public School } \\
\text { Private School }\end{array}$ & $\begin{array}{l}352(49.6) \\
357(50.4)\end{array}$ & $\begin{array}{l}390(51) \\
375(49)\end{array}$ & $\begin{array}{l}742(50.3) \\
732(49.7)\end{array}$ \\
\hline $\begin{array}{l}\text { Nutricional Status } \\
\text { Low weight } \\
\text { Normal weight } \\
\text { Overweight } \\
\text { Obesity }\end{array}$ & $\begin{aligned} 22 & (3.1) \\
497 & (70.1) \\
107 & (15.1) \\
83 & (5.6)\end{aligned}$ & $\begin{array}{l}34(4.4) \\
547(71.5) \\
115(15) \\
69(4.7)\end{array}$ & $\begin{array}{c}56(3.8) \\
1044(70.8) \\
222(15.0) \\
152(10.4)\end{array}$ \\
\hline
\end{tabular}

${ }^{\mathrm{a}} \mathrm{M}=$ Mean; $\mathbf{S D}=$ Standard-Deviation 
The medium height, SAP and NC were significantly higher in males in both age groups and beyond these anthropometric indicators in the group of 15 to 17 years, male adolescents also had an average weight and waist circumference significantly higher. The averages for the anthropometric and blood pressure of adolescents stratified by age group are shown in Table 2 .

The NC average was significantly higher in male teenagers in all nutritional state gaps according to BMI (Table 3).

Table 2: Average values of anthropometric indicators and arterial pressure by gender and age in Sergipe, Brazil.

\begin{tabular}{|c|c|c|c|c|c|c|c|c|c|c|}
\hline \multirow[b]{3}{*}{ Variable } & \multicolumn{4}{|c|}{$12-14$ years } & \multicolumn{5}{|c|}{$15-17$ years } & \multirow[b]{3}{*}{$\mathrm{p}^{\star}$} \\
\hline & \multicolumn{2}{|c|}{$\begin{array}{c}\text { Male } \\
\mathbf{N}=\mathbf{3 0 7}\end{array}$} & \multicolumn{2}{|c|}{$\begin{array}{l}\text { Female } \\
N=402\end{array}$} & \multicolumn{3}{|c|}{$\begin{array}{c}\text { Male } \\
\mathrm{N}=351\end{array}$} & \multicolumn{2}{|c|}{$\begin{array}{l}\text { Female } \\
\mathrm{N}=414\end{array}$} & \\
\hline & M1 & DP2 & M1 & DP2 & $\mathrm{p}^{*}$ & M1 & DP2 & M1 & DP2 & \\
\hline Weight & 53.42 & 14.00 & 51.14 & 10.63 & 0.10 & 65.02 & 14.66 & 56.69 & 12.25 & $<0.001$ \\
\hline Height & 162.37 & 9.98 & 158.26 & 5.90 & $<0.001$ & 172.66 & 6.94 & 160.83 & 6.06 & $<0.001$ \\
\hline WCa & 70.54 & 11.45 & 68.74 & 8.37 & 0.11 & 74.87 & 11.29 & 71.19 & 8.87 & $<0.001$ \\
\hline $\mathrm{SAP}^{\mathrm{b}}$ & 110.14 & 12.52 & 105.71 & 10.44 & $<0.001$ & 117.91 & 12.07 & 108.53 & 11.36 & $<0.001$ \\
\hline $\mathrm{DAP}^{\mathrm{c}}$ & 66.17 & 8.83 & 66.17 & 7.48 & 0.42 & 67.91 & 8.45 & 67.54 & 7.99 & $<0.32$ \\
\hline$N C^{d}$ & 32.31 & 3.09 & 30.47 & 2.21 & $<0.001$ & 34.93 & 2.57 & 31.28 & 2.20 & $<0.001$ \\
\hline BMI & 20.04 & 3.90 & 20.35 & 3.70 & 0.11 & 21.75 & 4.46 & 21.86 & 4.22 & 0.44 \\
\hline
\end{tabular}

* Teste de Mann-Whitney $(p<0.05)$.

$1 \mathrm{M}=$ Medium; $2 \mathrm{SD}=$ Standard-Deviation; ${ }^{\mathrm{a}} \mathrm{WC}$ = Waist Circumference; ${ }^{\mathrm{b}} \mathrm{SAP}=$ Systolic Arterial Pressure; ${ }^{\mathrm{c} D A P}=$ Diastolic Arterial Pressure; ${ }^{\mathrm{d}} \mathrm{NC}=$ Neck Circumference; eBMI = Body Mass Index

Table 3: Neck Circumference (NC) average of teenagers from the samples according to BMI and gender.

\begin{tabular}{|c|c|c|c|c|c|}
\hline \multirow{3}{*}{$\begin{array}{c}\text { BMI } \\
\text { Classification }\end{array}$} & \multicolumn{4}{|c|}{ Gender } & \multirow{3}{*}{$\mathrm{p}^{*}$} \\
\hline & \multicolumn{2}{|c|}{ Male NC } & \multicolumn{2}{|c|}{ Female NC } & \\
\hline & $\mathbf{M}^{\mathrm{a}}$ & $S^{a}$ & $\mathbf{M}^{\mathbf{a}}$ & $D^{a}$ & \\
\hline Low Weight & 31.53 & 2.28 & 28.32 & 1.88 & $<0.001$ \\
\hline Eutrophic & 33.04 & 2.69 & 30.28 & 1.72 & $<0.001$ \\
\hline Overweight & 34.74 & 2.38 & 32.31 & 1.80 & $<0.001$ \\
\hline Obesity & 36.74 & 2.30 & 34.54 & 2.36 & 0.003 \\
\hline
\end{tabular}

* Mann-Whitney test; $1 \mathrm{M}=$ Medium; 2SD = Standard Deviation

Table 4. Correlation between Neck Circumference and Age, Waist Circumference, BMI and Blood Pressure.

\begin{tabular}{|c|c|c|}
\hline \multirow[b]{2}{*}{ VARIABLES } & \multicolumn{2}{|c|}{ Neck Circumference } \\
\hline & $\begin{array}{c}\text { 12-14 Ages } \\
(N=458) \\
r(p)^{*}\end{array}$ & $\begin{array}{c}\text { 15-17 Ages } \\
(N=494) \\
r(p)^{*}\end{array}$ \\
\hline Waist Circumference & $0.692(<0.001)$ & $0.619(<0.001)$ \\
\hline Body Mass Index & $0.658(<0.001)$ & $0.494(<0.001)$ \\
\hline Systolic Arterial Pressure & $0.514(<0.001)$ & $0.530(<0.001)$ \\
\hline Diastolic Arterial Pressure & $0.286(<0.001)$ & $0.198(<0.001)$ \\
\hline
\end{tabular}

* Spearman Coefficient Correlation.

The group of 12 to 14 years old presented a positive correlation between $\mathrm{NC}$ and $\mathrm{WC}(\mathrm{r}=0.692$; $\mathrm{p}<0.001)$; NC and BMI $(\mathrm{r}=0.658 ; \mathrm{p}<0.001)$ and $\mathrm{NC}$ and Systolic Arterial Pressure $(r=0.514 ; \mathrm{p}<0.001)$; and in the age group between 15 and 17 years old the $\mathrm{NC}$ and WC $(\mathrm{r}=0.619 ; \mathrm{p}<0.001)$; NC and BMI $(\mathrm{r}=0.494$; $\mathrm{p}<0.001)$ and $\mathrm{NC}$ and Systolic Arterial Pressure $(\mathrm{r}=0.530 ; \mathrm{p}<0.001)$. Table 2 presented all values found in the analysis of associations between the anthropometric variables Blood Pressure and NC.

The cutoff points for the determination of overweight according to $\mathrm{NC}$ for male teenagers in the age group of 12 to 14 years old were $34.1 \mathrm{~cm}$ and for female
32.05. Further, male teenagers in the group of 15 to 17 years old were $36.85 \mathrm{~cm}$ and the female $32.95 \mathrm{~cm}$.

Considering cutoff points for the determination of obesity according to $\mathrm{NC}$ for male teenagers in the age group of 12 to 14 years old was $34.9 \mathrm{~cm}$ and female 33.85 $\mathrm{cm}$. Meanwhile, male teenagers in the group of 15 to 17 years old the cutoff point for obesity was $38.4 \mathrm{~cm}$ and females $35.85 \mathrm{~cm}$.

Table 5 presented the AUC and optimal cutoff points for NC equivalents to overweight, and obesity according to BMI classification for each of the age groups, including the sensibility (SE), PPV, specificity (SP) and corresponding NPV 
Table 5. Cutoff points of Neck Circumference (NC) for the determination of overweight and obesity in female and male teenagers according to age groups

\begin{tabular}{|c|c|c|c|c|c|c|c|c|c|}
\hline & & AUC & Cutoff & SE & SP & PPV & NPV & $\begin{array}{l}\text { PPVI } \\
\text { NPV }\end{array}$ & ACC \\
\hline & Male & & & & & & & & \\
\hline & $12-14$ & 81.8 & 34.10 & 59 & 89 & 69 & 84 & 0.82 & 74 \\
\hline \multirow[t]{6}{*}{ Overweight } & $15-17$ & 85.2 & 36.85 & 58 & 91 & 67 & 87 & 0.77 & 75 \\
\hline & Female & & & & & & & & \\
\hline & $12-14$ & 89 & 32.05 & 60 & 94 & 80 & 87 & 0.92 & 77 \\
\hline & $15-17$ & 86.7 & 32.95 & 63 & 95 & 79 & 89 & 0.89 & 79 \\
\hline & Male & & & & & & & & \\
\hline & $12-14$ & 84.5 & 34.90 & 70 & 89 & 52 & 95 & 0.55 & 80 \\
\hline \multirow[t]{4}{*}{ Obesity } & $15-17$ & 89.3 & 38.40 & 59 & 99 & 92 & 95 & 0.97 & 79 \\
\hline & Female & & & & & & & & \\
\hline & $12-14$ & 94.8 & 33.85 & 59 & 99 & 88 & 96 & 0.92 & 79 \\
\hline & $15-17$ & 91.1 & 35.85 & 47 & 98 & 71 & 96 & 0.74 & 73 \\
\hline
\end{tabular}

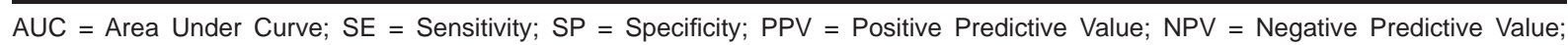
$\mathrm{ACC}=$ Accuracy .

\section{DISCUSSION}

Older male adolescents presented higher values for weight, height, WC, NC and SAP. NC was significantly correlated with all anthropometric indicators and with SAP, similar to the results found by Fitch et al. ${ }^{12}$, Tibana et al. ${ }^{13}$, Stabe et al. ${ }^{14}$ Frizon and Buscaini ${ }^{15}$ and Silva et al. ${ }^{16}$

Based on these results, NC can be used as a simple measure in routine clinical practice, and be considered as a relevant anthropometric value, being able to identify obesity levels, becoming an efficient strategy to detect this nutritional disorder in public health.

Related to NC cutoff points, we used as reference the BMI/age according to WHO curves (2007). Nafiu et al. ${ }^{17}$ determined the cutoff points of $\mathrm{NC}$ for the identification of children with overweight and obesity based on the BMI classification and growth graphics of Centers for Disease Control and Prevention (CDC) ${ }^{18}$.

Comparing the results of sensibility and specificity, our study represented a lower sensibility in both ages groups for teenagers versus the $82.5 \%$ for all male and $79.7 \%$ for female teenagers found by Nafiu et al. ${ }^{17}$ But specificity is higher for all group ages and for both sex than the values found by the cited authors. ${ }^{17}$

The study described by Nafiu et al. ${ }^{17}$ did not present the predominance of $\mathrm{NC}$ over $\mathrm{BMI}$, considering the traditional overweight classification method. According to Kim et al. ${ }^{19}$, this limitation is due to the fact that the CDC graphics are not precise enough to serve as reference method for the development of a group of cutoff points, because they have included a group of children, $70 \%$ of the total sample, that were submitted to various surgery outpatient clinics in a pediatric hospital. Therefore, the cutoff points developed in this particular group of children do not classify precisely overweight and obesity when submitted to healthy children. ${ }^{19}$

The present study also presented a higher specificity for all group ages and for both sexes versus the $85.0 \%$ of male teenagers and $91.3 \%$ of female teenagers, found in a study with healthy children. ${ }^{19}$

Related to the study developed by Kim et al. ${ }^{19}$, the relatively small number of individuals participating (92) may limit analysis and stratification of the results by age and may not precisely compare the NC with other anthropometric values, being compared with BMI.

In our population, obesity prevalence $(10.4 \%)$ was above the one found in ERICA study ${ }^{10}$ for the Brazilian northeast area $(7.4 \%)$ and national prevalence $(8.4 \%){ }^{20}$

This elevated percentage of obese teenagers represents an important detection of this damage to health in students both in private and public schools, in the cities studied.

Salvador et al. found a low prevalence of nutritional deficiencies and high prevalence of indicators associated to obesity in individuals aged 8 to 17 years old in schools located at 3 administrative regions in the city of Vitória, Brazil ${ }^{21}$. In many countries such as Brazil, that went through rapid economic growth, many individuals were exposed to food privation during infancy, entering the adolescence in a completely different scenario of food availability, specially of ultra-processed food, which are highly associated with obesity risk. ${ }^{22}$

The results here obtained could show that NC measurement is an important tool to identify overweight and obese teenagers. The observed results are consistent, since a higher precision of the classification cutoff points of NC in healthy populations, a more representative quantification of individuals in different age groups was seen and when compared to the references used. This is the first study to propose and analyze precision of cutoff points in the NC measurements of overweight and obesity in a sample of Brazilian teenagers.

The neck circumference represented significant correlation among waist circumference and body mass index well stablished indicators of adiposity and can identify adolescents with high body mass index. 


\section{REFERENCES}

1. Instituto Brasileiro de Geografia e Estatística (IBGE). Pesquisa de orçamentos familiares 2008-2009. Aquisição alimentar domiciliar per capita Brasil e grandes regiões. Rio de Janeiro: IBGE; 2010.

2. Hingorjo MR, Qureshi MA, Mehdi A. Neck circumference as a useful marker of obesity: A comparison with body mass index and waist circumference. J Pak Med Assoc. 2012; 62(1):36-40.

3. Giugliano R, Melo ALP. Diagnosis of overweight and obesity in schoolchildren: use of body mass index international standard. J Pediatr (Rio J.) 2004; 80(2):129-34. DOI: http://dx.doi.org/10.1590/S002175572004000200010

4. Pinto ICS, Arruda IKG, Diniz AS, Cavalcanti AMT. Prevalence of overweight and obesity, according to anthropometric parameters, and association with sexual maturation in adolescent students. Cad Saúde Pública. 2010;26(9):1727-37. DOI: http://dx.doi.org/10.1590/S0102-311X2010000900006

5. Rezende FAC, Rosado LEFPL, Franceschinni SCC, Rosado GP, Ribeiro RCL. Aplicabilidade do índice de massa corporal na avaliação da gordura corporal. Rev Bras Med Esporte. 2010;16(2):90-94. DOI: http:// dx.doi.org/10.1590/S1517-86922010000200002

6. Vague $\mathrm{J}$. The degree of masculine differentiation of obesities: a factor determining predisposition to diabetes, atherosclerosis, gout, and uric calculous disease. Am J Clin Nutr. 1956;4(1):20-34.

7. Hatipoglu N, Mazicioglu MM, Kurtoglu S, Kendirci M. Neck circumference: An additional tool of screening overweight and obesity in childhood. Eur J Pediatr. 2010;169(6):733-9. DOI: http://dx.doi.org/10.1007/ s00431-009-1104-Z

8. Yang GR, Yuan SY, Fu HJ, Wan G, Zhu LX, Bu XL, et al. Neck circumference positively related with central obesity, overweight, and metabolic syndrome in Chinese subjects with type 2 diabetes: Beijing Community Diabetes Study 4. Diabetes Care. 2010;33(11): 2465-7. DOI: http://dx.doi.org/10.2337/dc10-0798

9. Mazici oglu MM, Kurtoglu S, Ozturk A, Hatipoglu N, Cicik B, Ustunbas HB. Percentiles and mean values for neck circumference in Turkish children aged 6-18 years. Acta Paediatr. 2010; 99(12): 1847-53. DOI: http://dx.doi.org/10.1111/j.1651-2227.2010.01949.x

10. Bloch KV, Cardoso MA, Sichieri R. Estudo dos Riscos Cardiovasculares em Adolescentes (ERICA): resultados e potencialidade. Rev Saúde Pública. 2016; 50(Suppl.1): 2s. DOI: http://dx.doi.org/10.1590/ S015188787.201605000SUPL1AP.

11. Martinez EZ, Louzada-Neto F, Pereira BB. A curva ROC para testes diagnósticos. Cad Saúde Pública. 2003;11(1):7-31.

12. Fitch KV, Stanley TL, Looby SE, Rope AM, Grinspoon SK. Relationship between neck circumference and cardiometabolic parameters in HIV-infected and non HIV-infected adults. Diabetes Care. 2011; 34(4):102631. DOI: http://dx.doi.org/10.2337/dc10-1983

13. Tibana RA, Teixeira TG, Farias DL, Silva AO, Madrid B, Vieira A, et al. Relação da circunferência do pescoço com a força muscular relativa e os fatores de risco cardiovascular em mulheres sedentárias. Einstein. 2012;10(3):329-34.DOI: http://dx.doi.org/10.1590/S1679-45082012000300013

14. Stabe C, Vasques AC, Lima MM, Tambascia MA, Pareja JC, Yamanaka A, et al. Neck circumference as a simple tool for identifying the metabolic syndrome and insulin resistance: results from the Brazilian Metabolic Syndrome study (BRAMS). Clin Endocrinol (Oxf). 2013;78(6):874-81. DOI: http://dx.doi.org/10.1111/ j.1365-2265.2012.04487.x

15. Frizon V, Boscaini C. Neck Circumference, Cardiovascular Disease Risk Factors and Food Consumption. Rev Bras Cardiol. 2013; 26(6):426-34.

16. Silva CC, Zambon MP, Vasques ACJ, Rodrigues AMB, Camilo DF, Antonio MARGM, et al. Circunferência do pescoço como um novo indicador antropométrico para predição de resistência à insulina e componentes da síndrome metabólica em adolescentes: Brazilian Metabolic Syndrome Study. Rev Paul Pediatr. 2014;32(2):221-9. DOI: http://dx.doi.org/10.1590/0103-0582201432210713

17. Nafiu OO, Burke C, Lee J, Voepel-Lewis T, Malviya S, Tremper KK. Neck circumference as a screening measure for identifying children with high body mass index. Pediatrics. 2010;126(2):e306-10. DOI: http:// dx.doi.org/10.1542/peds.2010-0242

18. Kuczmarski RJ, Ogden CL, Guo SS, Grummer-Strawn LM, Flegal KM, Mei Z, et al. 2000 CDC Growth Charts for the United States: methods and development. Vital Health Stat. 2002;11(246):1-190.

19. Kim Y, Lee J-M, Laurson K, Bai Y, Gaesser GA, Welk GJ. Accuracy of Neck Circumference in Classifying Overweight and Obese US Children. ISRN Obes. 2014; 781841. DOI: http://dx.doi.org/10.1155/2014/781841

20. Bloch KV, Klein CH, Szklo M, Kuschnir MCC, Abreu GA, Barufaldi LA, et al. ERICA: prevalências de hipertensão arterial e obesidade em adolescentes brasileiros. Rev. Saúde Pública. 2016;50(1):9s. DOI: http:// dx.doi.org/10.1590/S01518-8787.2016050006685

21. Salvador CCZ, Kitoko PM, Gambardella AMD. Nutritional status of children and adolescents: factors associated to overweight and fat accumulation. J Hum Growth Dev. 2014;24(3):313-9. DOI: http://dx.doi. org/10.7322/jhgd.88969 
This article is distributed under the terms of the Creative Commons Attribution 4.0 International License (http://creativecommons.org/licenses/by/4.0/), which permits unrestricted use, distribution, and reproduction in any medium, provided you give appropriate credit to the original author(s) and the source, provide a link to the Creative Commons license, and indicate if changes were made. The Creative Commons Public Domain Dedication waiver (http://creativecommons.org/publicdomain/zero/1.0/) applies to the data made available in this article, unless otherwise stated.

\section{RESUMO}

Objetivo: Identificar pontos de corte de acordo com a circunferência do pescoço (CP) para determinação dos níveis de excesso de peso em adolescentes.

Método: Estudo transversal com adolescentes entre 12 e 17 anos, residentes em dois municípios do nordeste brasileiro. Foram coletados dados antropométricos e Pressão Arterial (PA). Foi realizado o teste de Mann-Whitney para comparação dos dados e o Coeficiente de Correlação de Spearman para associação entre a CP e outras variáveis antropométricas como a idade, circunferência da cintura (CC), Índice de Massa Corporal (IMC) e a PA. Foi analisada a validade preditiva da CP na determinação de pontos de corte para identificação do excesso de peso nos adolescentes.

Resultados: A amostra foi composta por 1474 adolescentes com idade média de 14,59 $\pm 1,57$ anos, sendo $55,3 \%$ do gênero feminino. Foi encontrada uma correlação positiva entre CP e CC e CP e IMC. De acordo com a CP, os pontos de corte para identificação de sobrepeso na faixa etária entre 12 e 14 anos foi equivalente a $34,1 \mathrm{~cm}$ para meninos e $32,05 \mathrm{~cm}$ para meninas. Na faixa etária entre 15 e17 anos foi $36,85 \mathrm{~cm}$ para meninos e $32,95 \mathrm{~cm}$ para meninas. Os pontos de corte para obesidade na faixa etária entre 12 e 14 anos foi $34,9 \mathrm{~cm}$ para meninos e $33,85 \mathrm{~cm}$ para meninas. Na faixa etária entre 1517 anos, o ponto de corte para a obesidade foi $38,4 \mathrm{~cm}$ para meninos e $35,85 \mathrm{~cm}$ para meninas.

Conclusões: A Circunferência do Pescoço apresentou correlação significativa com a CC e o IMC, indicadores bem estabelecidos de adiposidade, podendo identificar adolescentes com sobrepeso e obesidade.

Palavras-chave: obesidade, antropometria, pescoço, nutrição do adolescente. 